\title{
Does Integration Occur on a Certain Day? The Case of the Lithuanian Stock Market
}

Rayenda Brahmana, Muath Asmar *

Abstract:

This paper explores the intersection between market integration and Weekend Effect by investigating the possibility of integration to occur in a certain day over the period of 1 January 1990 until 31 December 2010. The integration was retrieved from the intercept time varying rolling regression of Stehle's (1977) ICAPM Model. Meanwhile, the Weekend effect is captured by the intercept time varying rolling regression of French's (1980) Monday Effect Model. For robustness, we modified the French's Model to examine the seasonality inside market integration with Exchange Rate and Oil Prices as the control variable. This research remarks the seasonality of Lithuanian stock market integration.

Key words: Market Integration, Weekend Anomaly, Portfolio Benefit, Lithuanian Stock Market

JEL: F36, G14, G11

DOI: $10.2478 / \mathrm{v} 10033-011-0012-0$

\section{Introduction}

Stock market integration research has been extensively conducted and evolving over the past several years. However, exploration in this area has continued because of its contribution to the body of knowledge and industrial practices. One of the important issues of market integration is how it can appear in most stock markets in the world.

Interestingly, just like market integration, most stock markets also experience the weekend effect, a calendar anomaly associated with the distribution of daily common stock returns. The weekend effect refers to the repeated returns cycle on a certain day (usually Monday). Those particular returns have had a negatively high dispersal compared to other days. Such a phenomenon has been verified mainly in the developed market over the past two decades.

Related back to market integration, this event indicates ignorance of the equity risk premium and diminishing potential cross-border diversification. To a finance manager on the corporate level, stock market integration indicates that there are fewer opportunities to acquire capital at lower cost across borders, awarding the discouragement of foreign listing activities. The other contributions from stock market integration cater to the potential for welfare gains (see Cole and Obstfeld, 1992; Van Wincoop, 1994; Lewis, 1996) and beneficial consequences on long-term economic growth (see Obstfeld, 1994; Devereux and Smith, 1994; Levine and Zervos, 1996, 1998; Bekaert et al., 2001, 2005).

However, the recent catastrophic economic events such as the Asian Monetary Crisis 1997 and the Global Crisis of 2008 have countered those early findings, showing the high correlation of dossiers among stock

\footnotetext{
* Rayenda Brahmana

Finance Cluster. School of Management, Universiti

Sains Malaysia

E-mail: raye_brahm@yahoo.com

\section{Muath Asmar}

Finance Cluster. School of Management, Universiti Sains Malaysia
} 